\title{
Effect of green tea on the gastrointestinal absorption of amoxicillin in rats
}

\author{
Tivadar Kiss ${ }^{1,2}$, Zoltán Timár ${ }^{3}$, Andrea Szabó ${ }^{2,4}$, Anita Lukács ${ }^{2,4}$, Viktória Velky ${ }^{3}$, Gábor Oszlánczi ${ }^{2,4}$, Edina Horváth ${ }^{4}$, \\ István Takács ${ }^{1}$, István Zupkó ${ }^{2,5}$ and Dezső Csupor ${ }^{1,2^{*}}$ (D)
}

\begin{abstract}
Background: The investigation of food-drug and plant-drug interactions has become increasingly important. In case of antibiotics, it is essential to achieve and maintain a plasma concentration sufficient for the antimicrobial action. Although, on theoretical basis, the interaction of polyphenols and antibiotics may be hypothesized, experimental data are lacking to assess its clinical relevance. The aim of our study was to assess the interaction between one of the most widely used antibiotics, amoxicillin, and green tea, the most frequently consumed drink with high polyphenol content.
\end{abstract}

Methods: The effects of green tea on the plasma level of amoxicillin was studied in an in vivo experiment in rats. The plasma level of amoxicillin was monitored by LC-MS/MS for 240 min after oral administration. The polyphenol content of green tea was determined by the Folin-Ciocalteu method.

Results: The peak plasma concentration of amoxicillin significantly decreased upon its co-administration with green tea, although the $\mathrm{AUC}_{0-240}$ of the antibiotic did not decrease significantly in the group treated with amoxicillin suspended in green tea.

Conclusions: Our results suggest a potentially relevant interaction between green tea and amoxicillin, worth being further studied in humans.

Keywords: Amoxicillin; green tea, Camellia sinensis, Pharmacokinetics, LC-MS/MS, Interaction

\section{Background}

Optimal dosing and timing, as well as the route of administration and justified use essentially influence the outcome of antibiotic therapy. The excessive use of antibiotics, including overuse and inappropriate application (including using suboptimal doses) of antimicrobial agents fosters bacterial resistance, recognized as one of the most urgent global public health threats, and being the main reason for nosocomial infections [1]. Therefore, the World Health Organization (WHO) makes continuous efforts to raise the awareness of healthcare professionals and patients about proper antibiotic use.

Some aspects of antibiotic interactions have been extensively studied. It is well known that the co-

\footnotetext{
* Correspondence: csupor.dezso@pharmacognosy.hu

1 Department of Pharmacognosy, Faculty of Pharmacy, University of Szeged, Eötvös utca 6, Szeged H-6720, Hungary

${ }^{2}$ Interdisciplinary Centre for Natural Products, University of Szeged, Eötvös utca 6, Szeged H-6720, Hungary

Full list of author information is available at the end of the article
}

administration of several antibiotics with milk products should be avoided as bivalent ions, i.e. calcium and magnesium in milk form complexes with these pharmacons, thereby decreasing their absorption [2]. Although some food and herb interactions with antibiotics have also been described, the number of studies focusing on this issue is limited. For the majority of medicinal herbs it is still undiscovered whether they alter the pharmacokinetics of antibiotics.

However, there are reasonable theoretical considerations that suggest the risk of potential interactions. Some components of medicinal plants may interfere with the bioavailability of antibiotics by decreasing their absorption. The two most important family of compounds that may potentially affect the pharmacokinetics of antibiotics include fibres and polyphenols, which most frequently occur in commonly used plants. These compounds may affect the absorption of different drugs via chemical or physical interactions. The effect of fibres 
(chemically polysaccharides) is non-specific, hence these compounds affect the bioavailability of various medicines, such as digoxin, lovastatin, metformin and penicillins [3]. Polyphenols are known to react chemically with amine-containing molecules resulting in precipitation which may lead to decreased bioavailability [4]. Although several drug molecules contain amine functionalities, this potential interaction has not been studied in detail. This possible interaction may be avoided by consuming polyphenol-rich food (e.g. fruits) separately from medicines, however, the risk of taking medicines with drinks containing polyphenols is neglected. The most popular drink with a remarkably high polyphenol content is tea, especially green tea. Tea is the most widely consumed beverage aside from water, and its consumption is growing worldwide [5]. Although, globally, black tea is Although, globally, the most frequently consumed the most frequently, even in countries where it is the top type of tea (e.g. Morocco, Turkey, Ireland and the United Kingdom), green tea consumption shows an increasing popularity due to a growing consumer interest toward healthier beverages [6]. Green tea is one of the most popular beverages in Japan, China, as well as in some countries in North Africa and the Middle East [7]. Generally, $40-70 \%$ of the Japanese population consumesconsume green tea regularly (at least 1 cup/day) $[8,9] . I n$ Europe is consumed as the top In Europe, green tea is the most type of tea in Belgium, Denmark and France [10]. The health benefits of green teaThe health benefit of green tea has been extensively studied: it has proved antioxidant, anti-inflammatory, anticarcinogenic, and antimicrobial effects $[11,12]$. These health promoting effects are mainly associated with its polyphenol content, that may constitute up to $30 \%$ of the dry leaf weigh [7].

Based on its highly frequenthigh consumption, green tea is very likely to be consumed with medicines, including antibiotics. In a recent review [13], the interaction between green tea and clinically prescribed medications was summarized as follows: the plasma concentration of some drugs (e.g. diltiazem, clozapine, tamoxifen) changed significantly when they were administered concurrently with green tea/EGCG to male Sprague-Dawley rats. Nevertheless, the interaction between green tea and antibiotics has been poorly investigated. The majority of the available studies have been carried out in vitro, primarily to explore the potential synergistic pharmacodynamic interactions [14, 15]. Egyptian scientists found that even diluted green tea enhanced the bactericidal activity of several antibiotics against 28 microorganisms in vitro, and moreover, it increased the susceptibility of drug-resistant bacteria [16]. Noormandi et al. thoroughly summarized the synergistic effect of green tea on antibiotic treatment of urinary tract infections, however, they emphasized that despite the promising results of in vitro studies, human and animal studies are needed [17] Based on the potential antagonistic (inhibition of absorption) and agonistic (increase of antibacterial activity) interactions, the overall effect of the concomitant consumption of green tea and antibiotics seems to be contradictorycontradictory.

Amoxicillin is one of the most commonly used antibiotics in primary care, prescribed either alone or in combination with clavulanic acid, with a remarkable dominance in inpatient therapy $[18,19]$. It is reported that high-fiber diet reduces the bioavailability of amoxicillin [20-22], while regular type food intake [21, 23, 24] does not affect it. Interestingly, while most antibiotics interact with calcium, and thus the concomitant consumption of milk and antibiotics is not recommended, this phenomenon was not observed for amoxicillin $[25,26]$. However, the amoxicillin molecule contains amine functionalities, thus it might be subject to interaction with polyphenols.

The interaction between green tea extract and amoxicillin was studied in vitro only. In one study synergistic interactions between ampicillin, a $\beta$-lactam antibiotic alike amoxicillin, and green tea against Staphylococcus aureus were described [15].. Also, in an in vitro study, Passat found that the water extract of green tea leaves has synergistic effect on some antibiotics including amoxicillin, while it has and antagonistic effect on other antibiotics used against urinary tract $E$. coli isolates [27].

As in vivo or toxicokinetic studies are still missing in the literature, thet aim of our research was to study this potentially relevant interaction, i.e. the effect of green tea on the absorption of amoxicillin, in an in vivo experiment on rats, as a preliminary step for a suggested human study. To the best of our knowledge, our work is the first in vivo toxicokinetic investigation of this issue in vivo.

\section{Methods \\ Experimental substances}

Amoxicillin trihydrate (product number: 31586) and potassium clavulanate (product number: 33454) were purchased from Sigma-Aldrich. Green tea (China-Chun Mee) was obtained from Hungary (Latin Negyed Ltd., Hungary). All the solvents were of LC-MS grade (VWR, Hungary).

\section{Determination of polyphenol content}

Total polyphenol content, determined as pyrogallol equivalent, was measured according to the method described in the European Pharmacopoeia [28]. In a round-bottomed flask $0.5 \mathrm{~g}\left(\mathrm{~m}_{1}\right)$ powdered green tea was extracted with $150 \mathrm{ml}$ of water in a water-bath for 40 min. After cooling under running water, it was transferred to a $250 \mathrm{ml}$ volumetric flask and was diluted to 
$250.0 \mathrm{ml}$ with water. The extract was filtered through a filter paper of $125 \mathrm{~mm}$ in diameter. The first $50 \mathrm{ml}$ of the filtrate was discarded. $5.0 \mathrm{ml}$ of filtrate was diluted to $25.0 \mathrm{ml}$ with water. $2.0 \mathrm{ml}$ of this diluted extract was transferred to a $10 \mathrm{ml}$ volumetric flask, $1.0 \mathrm{ml}$ of twofold dilution of Folin-Ciocalteu reagent was added, and the mixture was diluted to $10.0 \mathrm{ml}$ with a $290 \mathrm{~g} / \mathrm{l}$ solution of sodium carbonate. After $30 \mathrm{~min}$ absorbance at $760 \mathrm{~nm}\left(\mathrm{~A}_{1}\right)$ was measured. For a standard solution $0.0500 \mathrm{~g}\left(\mathrm{~m}_{2}\right)$ of pyrogallol was dissolved in water immediately before use, and diluted to $100.0 \mathrm{ml}$ using the same solvent. $5.0 \mathrm{ml}$ of this solution was diluted to $100.0 \mathrm{ml}$ with water. $2.0 \mathrm{ml}$ of this diluted pyrogallol solution was transferred to a $10 \mathrm{ml}$ volumetric flask, 1.0 $\mathrm{ml}$ of two-fold dilution of Folin-Ciocalteu reagent was added, and the mixture was diluted to $10.0 \mathrm{ml}$ with a $290 \mathrm{~g} / \mathrm{l}$ solution of sodium carbonate. After $30 \mathrm{~min}$ absorbance at $760 \mathrm{~nm}\left(\mathrm{~A}_{2}\right)$ was measured. For the calculation of total polyphenols as pyrogallol equivalent (PGE, \%), the next formula was used:

$$
\frac{62.5 \cdot A_{1} \cdot m_{2}}{A_{2} \cdot m_{1}}
$$

\section{Test animals and animal care}

24 male SPF Wistar rats, weighing 276-300 g at the beginning of the study, were used in the experiment (purchased from Toxi-Coop Zrt., Hungary). After 5 days of acclimatization the rats were divided into two wellbalanced groups according to body weight (antibiotic only group (AM) and antibiotic plus green tea group (AMG), 12 animals/group). The number of animals per group was calculated to maximize the number of blood sampling occasions while minimizing the number of animals used for blood sampling per occasion. As environmental enrichment, unbleached, clean paper tubes were provided for the rats. Three rats per cage were placed on dust-free wood shavings as bedding material. Animals were housed under standard climatic conditions (22$24^{\circ} \mathrm{C}, 30-70 \%$ relative humidity, $12 \mathrm{~h}$ light/dark cycle with light starting at 6:00 a.m.) with free access to tap water and restricted access to certified rodent pellet. During the whole procedure, the regulations of the Hungarian Act No. XXVIII of 1998 on the protection and care of animals were strictly followed. Every procedure (handling, treatment, anaesthesia) executed in this experiment was approved by the Committee on Ethics of Animal Experiments of the University of Szeged and the Directorate of Food Safety and Animal Health Care, Government Agency of Csongrád County (Permit number: XXI./151/2013.). All efforts were made to minimize animal suffering.

\section{Administration of the antibiotic and green tea}

The OECD Guidelines No. 417 [29] and No. 423 [30] were followed during the experiment. Dose selection was based on Ishizaki [31] and Woodnutt [32] and was adjusted to bioanalytical detection rate in the samples. The suspension of amoxicillin and clavulanic acid (7:1 w/w; dose: $100 \mathrm{mg}$ amoxicillin/kg b.w.) was administered per os in single $1 \mathrm{ml} / \mathrm{kg}$ b.w. dose. The suspensions were prepared using either distilled water (AM group) or green tea infusion (AMG group). The suspensions were prepared freshly, no earlier than an hour before treatment, and were homogenized with vortex right before administration. Green tea infusion was prepared using $15 \mathrm{~g}$ of drug (green tea leaves) and $100 \mathrm{ml}$ of boiling water, and after $5 \mathrm{~min}$ of maceration the extract was filtered on a tea-strainer. The room temperature filtrate was used for the preparation of the antibiotic suspension applied in the AMG group.

Access to rodent chow was restricted to approximately $10 \mathrm{~g}$ for a 16-h-period preceding treatment to follow the advice of the OECD Guideline No. 423. Treatment modelled human medication intake. Right before the treatment, the body weights of the animals were measured individually in order to precisely calculate the amount of suspension to be given. The oral administration of AM or AMG took place outside the cage, executed by a round-ended gastric tube. Six animals were treated daily in the mornings, consecutively, with 5-min delays.

\section{Blood sampling}

The number of occasions for blood sampling were determined according to the pharmacokinetics of the test substance [32, 33]. Altogether, blood samples were taken six times: 30, 60, 90, 120, 180, and 240 min after the administration of AM/AMG. Considering the limited amount and occasions of blood sampling executable per animal (8 times at a maximum [34]), only 3 samples per animal were taken during the six-hour investigation time. To make sure that we obtain enough blood samples for the pharmacokinetic measurements, two animals were used for the total kinetic measurement. Accordingly, a total of twelve rats were used to obtain six data for each time point of the kinetics. The sampling protocol is given in Table 1.

Before each blood sampling the animals had been warmed with an infrared lamp for thirty minutes in order to dilate the tail veins to ease blood sampling. At the first sampling occasion, the firmly but securely restrained rat was placed on a warm pad, and a Vasofix Certo $24 \mathrm{G} \mathrm{3/4}(0,7 \times 19 \mathrm{~mm})$ intravenous catheter was placed in one of the lateral tail veins. To prevent the dislocation of the sampling needle a mild aether anaesthesia was provided under a ventilation hood to relax the 
Table 1 Sampling protocol. Times of blood sampling after treatment (30-240 min), showing which animals were used for blood sampling at each time point

\begin{tabular}{|c|c|c|c|c|c|c|c|c|c|c|c|c|}
\hline \multirow[b]{4}{*}{$30^{\prime}$} & \multicolumn{12}{|c|}{ Code number of the animals } \\
\hline & \multicolumn{6}{|c|}{ Amoxicillin (AM) } & \multicolumn{6}{|c|}{ Amoxicillin + green tea (AMG) } \\
\hline & \multicolumn{3}{|c|}{ 1st treatment day } & \multicolumn{3}{|c|}{ 2nd treatment day } & \multicolumn{3}{|c|}{ 3rd treatment day } & \multicolumn{3}{|c|}{ 4th treatment day } \\
\hline & 4 & 5 & 6 & 10 & 11 & 12 & 16 & 17 & 18 & 22 & 23 & 24 \\
\hline $60^{\prime}$ & 1 & 2 & 3 & 7 & 8 & 9 & 13 & 14 & 15 & 19 & 20 & 21 \\
\hline $90^{\prime}$ & 4 & 5 & 6 & 10 & 11 & 12 & 16 & 17 & 18 & 22 & 23 & 24 \\
\hline $120^{\prime}$ & 1 & 2 & 3 & 7 & 8 & 9 & 13 & 14 & 15 & 19 & 20 & 21 \\
\hline $180^{\prime}$ & 4 & 5 & 6 & 10 & 11 & 12 & 16 & 17 & 18 & 22 & 23 & 24 \\
\hline $240^{\prime}$ & 1 & 2 & 3 & 7 & 8 & 9 & 13 & 14 & 15 & 19 & 20 & 21 \\
\hline
\end{tabular}

animal when it was essential, by placing a small tube with a cotton bud containing $0.2 \mathrm{ml}$ aether to the nostril of the animal for a couple of seconds with careful supervision. A minimum of $0.2 \mathrm{ml}$ of blood samples were collected in a plastic tube, followed by injecting $0.12 \mathrm{ml}$ of heparin into the catheter and finally closing and fixing it to the tail using an adhesive tape [34]. At each following sampling occasion, a couple of blood drops were let out of the catheter before taking blood. In-between the sampling occasions the rats were awoke. The need for anaesthesia during sampling was negligible. Administration and sampling volumes are shown in Table 2.

After the sampling period the animals were overanaesthetized (euthanized) with isoflurane inhalation. A precision vaporizer with induction chamber and waste gas scavenger was used. An isoflurane concentration of over $5 \%$ in $100 \%$ oxygen was slowly achieved and continued until one minute after breathing stopped.

\section{Quantification of amoxicillin in plasma samples}

During blood sample processing the serum was separated from the clotted fraction by centrifugation (2700 G, $10 \mathrm{~min}$ ). $50 \mu \mathrm{l}$ of each centrifuged plasma sample was pipetted into $250 \mu \mathrm{l} \mathrm{MeOH}$ on a $0.5 \mathrm{~mL}$ 96-well Costar plate and cooled to $4{ }^{\circ} \mathrm{C}$ for $1 \mathrm{~h}$. Samples were centrifuged (2000 rcf) for $30 \mathrm{~min}$ at $8{ }^{\circ} \mathrm{C}$. $50 \mu \mathrm{l}$ supernatant was taken and evaporated. Calibration standards were prepared and injected directly into the LC-MS/MS apparatus. The concentration of amoxicillin and clavulanic acid was measured using an Agilent 1290 HPLC coupled to an Agilent 6470A Triple Quadrupole Mass Spectrometer equipped with an RP column (Luna $3 \mu$ C8(2) $100 \AA 50 \times 2 \mathrm{~mm}$; Phenomenex 00B-4251-B0). Isocratic elution was applied $(85 \%$ of $0.1 \% \mathrm{HCOOH}$ aqueous solution; $15 \%$ of $0.1 \% \mathrm{HCOOH}$ in acetonitrile), the flow rate was $0.5 \mathrm{ml} / \mathrm{min}$ and column temperature was set to $40^{\circ} \mathrm{C}$.

\section{Statistical analysis}

Descriptive and summary statistics were calculated. All results are presented as means \pm standard error of the mean (SEM). The area under the amoxicillin plasma concentration-time curves $\left(\mathrm{AUC}_{0-240}\right)$ were calculated. The plasma concentrations and AUC curves for amoxicillin in the AM and AMG groups were compared using paired Student's t-test. A $p<0.05$ was considered as significant. All calculations were performed with the GraphPad software (GraphPad Prism v. 8.0.1).

\section{Results}

Total polyphenol content of green tea was $12.31 \pm 0.41 \%$ PGE. The plasma concentration of amoxicillin was monitored by LC-MS/MS measurements in 30-60-min-intervals for $240 \mathrm{~min}$. Changes of amoxicillin level are shown in Fig. 1. A significant between-group difference in the plasma concentrations of amoxicillin was observed at $60 \mathrm{~min}$ only, while at other time points the difference between the groups did not reach the level of statistical significance. However, the highest plasma level of amoxicillin was significantly lower in the AMG group, which suggests an interaction between green tea polyphenols and the antibiotic.

Comparing the $\mathrm{AUC}_{0-240}$ for the two treatment groups (AM and AMG, $N=6$ both) a slight decrease in amoxicillin absorption was observed in the AMG group, however, the difference did not reach statistical significance (Fig. 2).

\section{Discussion}

The aim of our study was to assess the presumable interaction between a frequently used antibiotic (the combination of amoxicillin and clavulanic acid) and green tea infusion, in a setting mimicking the intake of the medicine with green tea.

The investigated tea was analytically characterized and was proved to be rich in polyphenols [35]. Based on literature, in vitro experiments demonstrate that catechins, the main polyphenolic compounds of green tea, do 
Table 2 Suspension (green tea +/- amoxicillin) volumes administered before sampling, and sampling volumes after treatment (30240 min) (AM: amoxicillin, AMG: amoxicillin + green tea)

\begin{tabular}{|c|c|c|c|c|c|c|c|c|c|c|c|}
\hline \multirow{2}{*}{$\begin{array}{l}\text { Group } \\
\text { code }\end{array}$} & \multirow{2}{*}{$\begin{array}{l}\text { Animal } \\
\text { code }\end{array}$} & \multirow{2}{*}{$\begin{array}{l}\text { Animal } \\
\text { weight (g) }\end{array}$} & \multirow{2}{*}{$\begin{array}{l}\text { Administered } \\
\text { suspension } \\
\text { volume (ml) }\end{array}$} & \multicolumn{8}{|c|}{ Volumes of blood samples taken } \\
\hline & & & & $30^{\prime}$ & $60^{\prime}$ & $90^{\prime}$ & $120^{\prime}$ & $180^{\prime}$ & $240^{\prime}$ & $300^{\prime}$ & $360^{\prime}$ \\
\hline \multirow[t]{12}{*}{ AM } & 1 & 285 & 0.29 & - & 0.50 & - & 0.45 & - & 0.55 & - & 0.50 \\
\hline & 2 & 292 & 0.29 & - & 0.50 & - & 0.40 & - & 0.60 & - & 0.60 \\
\hline & 3 & 287 & 0.29 & - & 0.60 & - & 0.50 & - & 0.75 & - & 0.55 \\
\hline & 4 & 285 & 0.29 & 0.48 & - & 0.45 & - & 0.50 & - & 0.80 & - \\
\hline & 5 & 273 & 0.27 & 0.52 & - & 0.20 & - & 0.30 & - & 0.90 & - \\
\hline & 6 & 281 & 0.28 & 0.45 & - & 0.40 & - & 0.55 & - & 0.60 & - \\
\hline & 7 & 267 & 0.27 & - & 0.30 & - & 0.60 & - & 0.60 & - & 0.80 \\
\hline & 8 & 285 & 0.29 & - & 0.65 & - & 0.70 & - & 0.70 & - & 0.90 \\
\hline & 9 & 287 & 0.29 & - & 0.70 & - & 0.50 & - & 0.70 & - & 1.00 \\
\hline & 10 & 285 & 0.29 & 0.70 & - & 0.60 & - & 0.50 & - & 0.25 & - \\
\hline & 11 & 288 & 0.29 & 0.70 & - & 0.30 & - & 0.30 & - & 0.20 & - \\
\hline & 12 & 290 & 0.29 & 0.65 & - & 0.60 & - & 0.55 & - & 0.30 & - \\
\hline \multirow[t]{12}{*}{ AMG } & 13 & 296 & 0.30 & - & 0.70 & - & 0.70 & - & 0.70 & - & 0.70 \\
\hline & 14 & 302 & 0.30 & - & 0.60 & - & 0.60 & - & 0.70 & - & 0.50 \\
\hline & 15 & 294 & 0.29 & - & 0.45 & - & 0.70 & - & 0.60 & - & 0.60 \\
\hline & 16 & 298 & 0.30 & 0.70 & - & 0.55 & - & 0.70 & - & 0.60 & - \\
\hline & 17 & 301 & 0.30 & 0.70 & - & 0.30 & - & 0.50 & - & 0.70 & - \\
\hline & 18 & 287 & 0.29 & 0.60 & - & 0.60 & - & 0.55 & - & 0.50 & - \\
\hline & 19 & 311 & 0.31 & - & 0.35 & - & 0.50 & - & 0.45 & - & 0.50 \\
\hline & 20 & 306 & 0.31 & - & 0.65 & - & 0.65 & - & 0.70 & - & 0.90 \\
\hline & 21 & 312 & 0.31 & - & 0.75 & - & 0.60 & - & 0.50 & & 0.60 \\
\hline & 22 & 307 & 0.31 & 0.50 & - & 0.50 & - & 0.7 & - & 0.70 & - \\
\hline & 23 & 292 & 0.29 & 0.50 & - & 0.80 & - & 1.00 & - & 1.50 & - \\
\hline & 24 & 301 & 0.30 & 0.45 & - & 0.30 & - & 0.60 & - & 0.70 & - \\
\hline
\end{tabular}

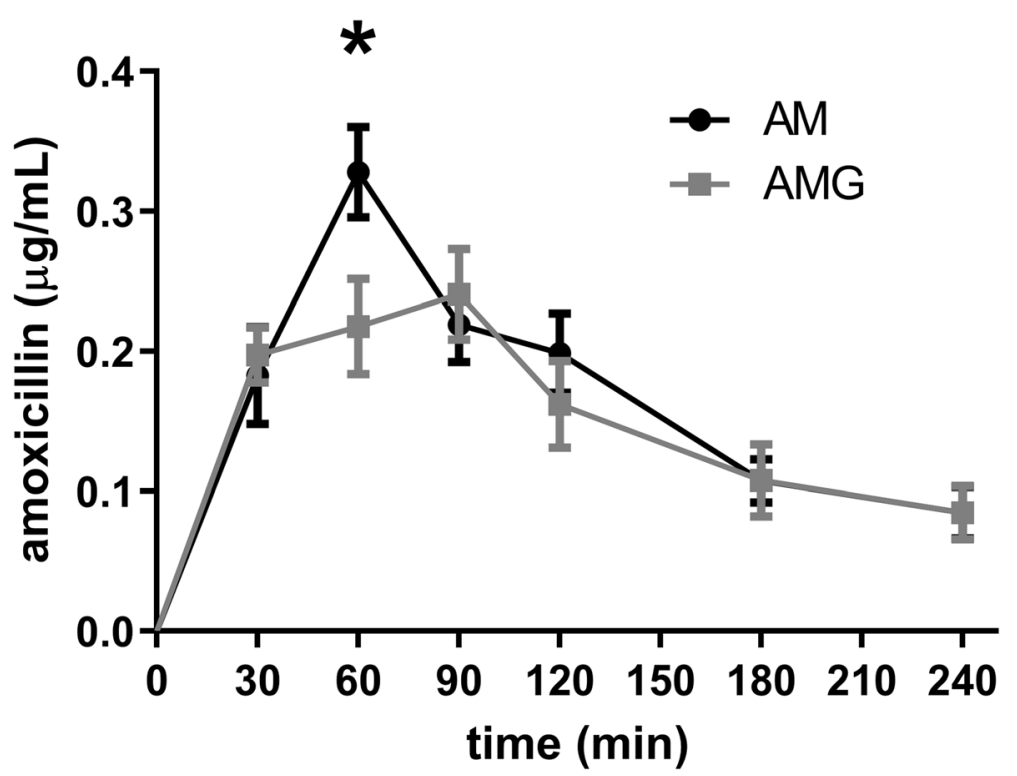

Fig. 1 Change in the plasma concentration of amoxicillin in the AM and AMG groups. Data are shown as mean \pm SEM $\left({ }^{*} p<0.05\right)$ 


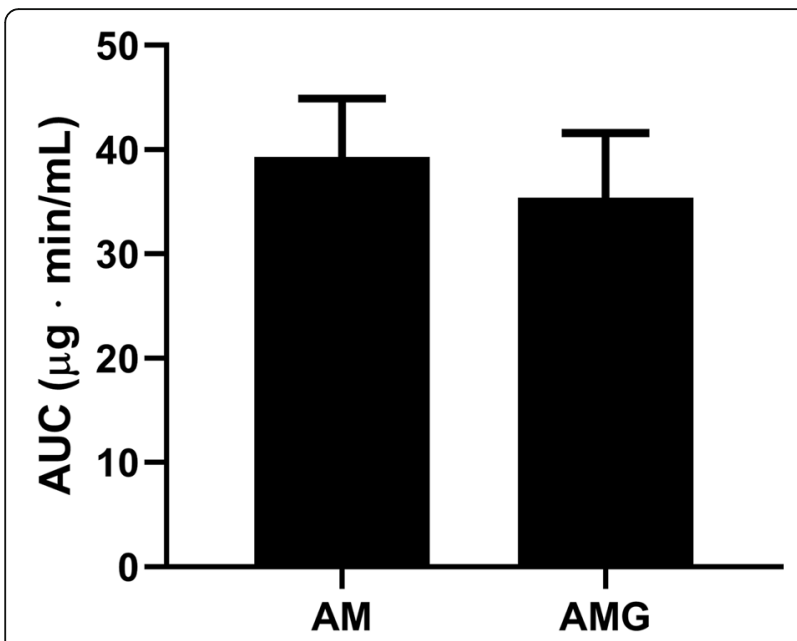

Fig. 2 AUC values in the AM and AMG groups. Data are shown as mean \pm SEM

influence the antimicrobial activity of amoxicillin, and the in vitro antibacterial effect of amoxicillin against Helicobacter pylori is significantly enhanced by the presence of epigallocatechin gallate [36]. Similarly, the synergistic effect of catechins and amoxicillin against Escherichia coli is also reported [17]. However, these in vitro findings have no relevance for the clinical efficacy of amoxicillin, since polyphenols have very low bioavailability, thus, in fact, the gastrointestinal tract is the space of potential interactions between these compounds and amoxicillin. An opposite effect was also observed in mice infected with methicillinresistant Staphylococcus aureus: in an in vivo experiment green tea extract was found to weaken the effect of amoxicillin after enteral administration (gastric perfusion) [37]. Our results confirm this finding, and offer a possible explanation for green tea ameliorating the antibacterial efficacy of amoxicillin treatment.

Not only green tea infusion, but also concentrated food supplements may contain high doses of catechins (up to $1000 \mathrm{mg}$ [38])). As these supplements are likely to be taken concomitantly with medications, the occurrence of an interaction between polyphenols/catechins and amoxicillin has relevance in real-life settings.

Although the AUC of amoxicillin did not decrease significantly during the observation period in our in vivo experiment, the concomitant administration of green tea induced a significant reduction in the peak plasma concentration of the antibiotic [37]. Despite the limitation of the study (small but reasonable sample size), our findings support the findings of a previously published animal experiment, and draw attention to the possibility of a pharmacokinetic interaction between green tea and amoxicillin upon human application. Further studies are needed to explore this interaction regarding per os human therapeutic use.

\section{Conclusions}

Due to its high polyphenol content green tea may interact with the absorption of amine-containing molecules, including antibiotics. This is the first report on the in vivo assessment of the interaction between a widely used antibiotic, amoxicillin, and green tea. Although the concomitant consumption of green tea did not alter the AUC of the antibiotic significantly within the observation period, the decrease in the peak plasma concentration of amoxicillin refers to an interaction of potential clinical relevance, worth being studied in human settings.

\section{Abbreviations \\ AM: Amoxicillin; AMG: Amoxicillin plus green tea; AUC: Area under the curve; $A \cup C_{0-240}$ : Area under curve in the first 240 min; EGCG: Epigallocatechin gallate; $\mathrm{HCOOH}$ : Formic acid; HPLC: High performance liquid chromatography; LC-MS/MS: Liquid chromatography/mass spectrometry; LC- MS/MS: Liquid chromatography/tandem mass spectrometry; MeOH: Methanol; MRSA: Methicillin-resistant Staphylococcus aureus; OECD: Organisation for Economic Co-operation and Development; PGE: Pyrogallol equivalent; rcf: relative centrifugal force; SEM: Standard error of mean; WHO: World Health Organization}

\section{Acknowledgements}

The authors thank Dora Bokor, PharmD, for proofreading the manuscript.

\section{Authors' contributions}

$D C$ conceived the study. DC, AS, AL, GO, and ZT designed the experiments. $A S, A L, G O, Z T, W, E H$, and TK performed the experiments and generated data. TK, DC, AS, IT and IZ analyzed the data. DC, TK, AS, AL wrote the manuscript. All the authors read and approved the final version of the manuscript.

\section{Funding}

Dezső Csupor was supported by the National Research, Development and Innovation Office [OTKA K115796], by the Economic Development and Innovation Operative Programme [GINOP-2.3.2-15-2016-00012] and by the János Bolyai Research Scholarship of the Hungarian Academy of Sciences. The funding sources played no role in, nor influenced study design, data collection, data analysis, data interpretation, or preparation of the manuscript.

\section{Availability of data and materials}

The datasets used and/or analysed during the current study are available from the corresponding author on reasonable request.

\section{Ethics approval and consent to participate}

All applicable international, national, and/or institutional guidelines for the care and use of animals were followed. Every procedure used in this experiment was approved by the Committee on Ethics of Animal Experiments of the University of Szeged and the Directorate of Food Safety and Animal Health Care, Government Agency of Csongrád County (Permit number: XXI./151/2013.). Consent to participate is not applicable.

\section{Consent for publication}

Not applicable.

\section{Competing interests}

The authors declare that they have no competing interests.

\section{Author details}

${ }^{1}$ Department of Pharmacognosy, Faculty of Pharmacy, University of Szeged, Eötvös utca 6, Szeged H-6720, Hungary. ${ }^{2}$ Interdisciplinary Centre for Natural Products, University of Szeged, Eötvös utca 6, Szeged H-6720, Hungary. ${ }^{3}$ SOLVO Biotechnology, Közép Fasor 52, Szeged H-6726, Hungary. ${ }^{4}$ Department of Public Health, Faculty of Medicine, University of Szeged, Dóm tér 10, Szeged H-6720, Hungary. ${ }^{5}$ Department of Pharmacodynamics 
and Biopharmacy, University of Szeged, Eötvös utca 6, Szeged H-6720, Hungary.

\section{Received: 27 April 2019 Accepted: 23 August 2019}

Published online: 30 August 2019

\section{References}

1. WHO. World antibiotic awareness week: WHO; 2018.

2. Bushra R, Aslam N, Khan AY. Food-drug interactions. Oman Med J. 2011;26:77-83 https://doi.org/10.5001/omj.2011.21.

3. Leibovitch ER, Deamer RL, Sanderson LA. Food-drug interactions: careful drug selection and patient counseling can reduce the risk in older patients. Geriatrics. 2004:59:19-22 32-3.

4. Adamczyk B, Simon J, Kitunen V, et al. Tannins and their complex interaction with different organic nitrogen compounds and enzymes: old paradigms versus recent advances. ChemistryOpen. 2017;6:610-4 https://doi. org/10.1002/open.201700113.

5. (2018) Tea in 2018: annual market overview. https://www.euromonitor.com/ tea-in-2018-annual-market-overview/report. Accessed 3 Jun 2019.

6. (2018) Current market situation and medium term outlook. Hangzhou.

7. Graham HNN. Green tea composition, consumption, and polyphenol chemistry. Prev Med (Baltim). 1992;21:334-50 https://doi.org/10.1016/00917435(92)90041-F

8. Zhang J-Y, Liao $Y-H$, Lin $Y$, et al. Effects of tea consumption and the interactions with lipids on breast cancer survival. Breast Cancer Res Treat. 2019; https://doi.org/10.1007/s10549-019-05253-5.

9. Mineharu Y, Koizumi A, Wada Y, et al. Coffee, green tea, black tea and oolong tea consumption and risk of mortality from cardiovascular disease in Japanese men and women. J Epidemiol Community Heal. 2011;65:230-40 https://doi.org/10.1136/jech.2009.097311.

10. Centre for the Promotion of Imports, CBI Ministry of Foreign Affairs. https:// www.cbi.eu/market-information/tea/trade-statistics. Accessed 3 Jun 2019.

11. Anand J, Rai N, Kumar N, Gautam P. Green tea: a magical herb with miraculous outcomes. Int Res J Pharm. 2012;3:139-48.

12. Serafini M, Del Rio D, Yao DN, et al. Health benefits of tea. In: Benzie IFF, Wachtel-Galor S, editors. Herbal medicine: biomolecular and clinical aspects. 2nd ed: CRC Press/Taylor \& Francis; 2011.

13. Albassam A, Markowitz J. An appraisal of drug-drug interactions with green tea (Camellia sinensis). Planta Med. 2017;83:496-508 https://doi.org/10.1055/ s-0043-100934.

14. Reygaert WC. The antimicrobial possibilities of green tea. Front Microbiol. 2014:5(434) https://doi.org/10.3389/fmicb.2014.00434.

15. Hacioglu M, Dosler S, Birteksoz Tan AS, Otuk G. Antimicrobial activities of widely consumed herbal teas, alone or in combination with antibiotics: an in vitro study. PeerJ. 2017;5:e3467 https://doi.org/10.7717/peer.3467.

16. (2008) Green tea helps beat superbugs, study suggests. ScienceDaily.

17. Noormandi A, Dabaghzadeh F. Effects of green tea on Escherichia coli as a uropathogen. J Tradit Complement Med. 2015;5:15-20 https://doi.org/10.1 016/j.jtcme.2014.10.005

18. Gillies M, Ranakusuma A, Hoffmann T, et al. Common harms from amoxicillin: a systematic review and meta-analysis of randomized placebocontrolled trials for any indication. CMAJ. 2015;187:E21-31 https://doi.org/ 0.1503/cmaj.140848.

19. Babraczy B, Benkő R, Borbás I, et al. Policy brief. Promoting the appropriate use of antibiotics to contain antibiotic resistance in human medicine in Hungary. Copenhagens; 2018.

20. Lutz M, Espinoza J, Arancibia A, et al. Effect of structured dietary fiber on bioavailability of amoxicillin. Clin Pharmacol Ther. 1987;42:220-4.

21. Neu HC. Antimicrobial activity and human pharmacology of amoxicillin. J Infect Dis. 1974;129:suppl:S123-31.

22. Neuvonen PJ, Elonen E, Pentikäinen PJ. Comparative effect of food on absorption of ampicillin and pivampicillin. J Int Med Res. 1977;5:71-6 https://doi.org/10.1177/030006057700500113.

23. Eshelman FN, Spyker DA. Pharmacokinetics of amoxicillin and ampicillin: crossover study of the effect of food. Antimicrob Agents Chemother. 1978;14:539-43.

24. Welling PG, Huang $H$, Koch PA, et al. Bioavailability of ampicillin and amoxicillin in fasted and nonfasted subjects. J Pharm Sci. 1977;66:549-52.

25. Ginsburg CM, McCracken GH, Thomas ML, Clahsen J. Comparative pharmacokinetics of amoxicillin and ampicillin in infants and children. Pediatrics. 1979;64:627-31.
26. Schmidt LE, Dalhoff K. Food-drug interactions. Drugs. 2002;62:1481-502 https://doi.org/10.2165/00003495-200262100-00005.

27. Passat DN. Interactions of black and green tea water extracts with antibiotics activity in local urinary isolated Escherichia coli. J Al-Nahrain Univ Sci. 2012;15:134-42 https://doi.org/10.22401/JNUS.15.3.19.

28. EDQM. Determination of tannins in herbal drugs. In: European Pharmacopoeia 5.0; 2005. p. 221.

29. OECD. Test No, vol. 417: Toxicokinetics; 2010

30. OECD (2002) Test no. 423: acute Oral toxicity - acute toxic class method.

31. Ishizaki J, Tsuda T, Suga Y, et al. Change in pharmacokinetics of mycophenolic acid as a function of age in rats and effect of coadministered amoxicillin/clavulanate. Biol Pharm Bull. 2012;35:1009-13.

32. Woodnutt G, Berry V. Efficacy of high-dose amoxicillin-clavulanate against experimental respiratory tract infections caused by strains of Streptococcus pneumoniae. Antimicrob Agents Chemother. 1999:43:35-40.

33. (2018) CLAVULIN Product Monograph.

34. NC3Rs National Centre for the replacement refinement and reduction of animals in research, Temporary cannula.

35. Dalluge JJ, Nelson BC. Determination of tea catechins. J Chromatogr A. 2000;881:411-24 https://doi.org/10.1016/S0021-9673(00)00062-5.

36. Yanagawa $Y$, Yamamoto $Y$, Hara $Y$, Shimamura T. A combination effect of epigallocatechin gallate, a major compound of green tea catechins, with antibiotics on Helicobacter pylori growth in vitro. Curr Microbiol. 2003:47:244-9.

37. Peng $Q$, Huang $Y$, Hou B, et al. Green tea extract weakens the antibacterial effect of amoxicillin in methicillin-resistant Staphylococcus aureus infected mice. Phytother Res. 2010;24:141-5 https://doi.org/10.1002/ptr.2952.

38. Younes $M$, Aggett $P$, Aguilar F, et al. Scientific opinion on the safety of green tea catechins. EFSA J. 2018;16(5239) https://doi.org/10.2903/j.efsa.201 8.5239

\section{Publisher's Note}

Springer Nature remains neutral with regard to jurisdictional claims in published maps and institutional affiliations.

Ready to submit your research? Choose BMC and benefit from

- fast, convenient online submission

- thorough peer review by experienced researchers in your field

- rapid publication on acceptance

- support for research data, including large and complex data types

- gold Open Access which fosters wider collaboration and increased citations

- maximum visibility for your research: over $100 \mathrm{M}$ website views per year

At BMC, research is always in progress.

Learn more biomedcentral.com/submissions 